\title{
Effect of 70\% Ethanol Extract and its Solvent Fractions of Artemisia afra (Jacq. Ex Willd.) against Pentylenetetrazole- Induced Seizure in Mice
}

\author{
Teketel Eristu Kediso $\left(\mathbb{D},{ }^{1,2}\right.$ Tesfaye Tolessa, ${ }^{2}$ Fikirte Getachew, ${ }^{3}$ Eyasu Makonnen $\mathbb{D D}^{4,5}$ \\ and Daniel Seifu ${ }^{6,7}$ \\ ${ }^{1}$ Department of Biomedical Sciences, College of Health Sciences, Arbaminch University, Arbaminch, Ethiopia \\ ${ }^{2}$ Department of Physiology, College of Health Sciences, Addis Ababa University, Addis Ababa, Ethiopia \\ ${ }^{3}$ Department of Biomedical Sciences, College of Health Sciences, Wachemo University, Hosanna, Ethiopia \\ ${ }^{4}$ Department of Pharmacology and Clinical Pharmacy, College of Health Sciences Addis Ababa University, Addis Ababa, Ethiopia \\ ${ }^{5}$ Center for Innovative Drug Development and Therapeutic Trials for Africa, College of Health Sciences, Addis Ababa University, \\ Addis Ababa, Ethiopia \\ ${ }^{6}$ Department of Biochemistry, College of Health Sciences, Addis Ababa University, Addis Ababa, Ethiopia \\ ${ }^{7}$ Division of Biomedical Sciences, Department of Biochemistry, University of Global Health Equity, Kigali, Rwanda
}

Correspondence should be addressed to Teketel Eristu Kediso; teketel.eristu@aau.edu.et

Received 7 December 2020; Accepted 10 June 2021; Published 18 June 2021

Academic Editor: Roberto K. N. Cuman

Copyright (C) 2021 Teketel Eristu Kediso et al. This is an open access article distributed under the Creative Commons Attribution License, which permits unrestricted use, distribution, and reproduction in any medium, provided the original work is properly cited.

\begin{abstract}
Introduction. Artemisia afra (Jacq. ex Willd.), commonly called African wormwood, is a highly aromatic perennial herb and a well-known medicinal plant, claimed to be effective and safe in the treatment of epilepsy. The whole-plant extract is traditionally used as an antiepileptic agent in Ethiopia. Aim of the Study. The aim of this study was, therefore, to evaluate the anticonvulsant effect of the hydroethanolic extract and solvent fractions of $A$. afra whole part in mice. Materials and Methods. The effects of A. afra hydroethanolic extract and its solvent fractions were evaluated against pentylenetetrazole- (PTZ-) induced convulsions in mice. The onset and duration of PTZ-induced convulsions were determined with hydroethanolic A. afra extract and its solvent fractions. Data were analyzed using a one-way analysis of variance (ANOVA) followed by post hoc Tukey's multiple comparisons test. $p<0.05$ was considered statistically significant. Results. The hydroethanolic extract of $A$. afra, with all the three doses of 250 , 500 , and $1000 \mathrm{mg} / \mathrm{kg}$, showed a significant delay $\left(504.833 \pm 62.835^{*} \mathrm{~s} ; p<0.05^{*} ; 551.833 \pm 47.69^{* *} \mathrm{~s} ; \quad p<0.01^{* *} ;\right.$ and $808.333 \pm 64.8^{* * *} \mathrm{~s} ; p<0.001^{* * *}$, respectively) in the mean onset of convulsion and a decrease $\left(17.000 \pm 1.88^{* * *} s, p<0.05^{*}\right.$; $13.000 \pm 1.8^{* *} \mathrm{~s}, p<0.01^{* *}$; and $7.833 \pm 1.07^{* * *} \mathrm{~s}, p<0.001$, respectively) in the mean duration of convulsion against PTZ-induced convulsion in a dose-dependent manner compared to the control ( $92.833 \pm 13.006 \mathrm{~s} ; 34.167 \pm 3.683 \mathrm{~s})$, and its anticonvulsant activity was significantly less compared to that of diazepam (1001.167 $\pm 68.430 \mathrm{~s} ; 4.500 \pm 0.619 \mathrm{~s})$. The solvent fractions, however, did not show anticonvulsant activity against PTZ-induced convulsion. Conclusion. Crude extract of A. afra has an anticonvulsant effect in mice. This might be attributed to the synergistic effects of two or more active ingredients present in the herb.
\end{abstract}

\section{Introduction}

A seizure is a high-frequency paroxysmal abnormal discharge from an aggregate of neurons in the cerebral cortex, which can be "nonepileptic" when evoked in an ordinary cerebrum by treatment (such as electric shock or chemical convulsant) or "epileptic" when occurring without evident provocation [1].

Epilepsy is a common neurological abnormality characterized by an unpredictable and periodic occurrence of a 
transient alteration of behavior including convulsions resulting from disordered synchronous and rhythmic firing of brain neurons [2]. It affects about $1 \%$ of the world population with an estimated frequency of 50 per 100,000 and 100 per 100,000 in technologically advanced and developing nations, respectively [3].

Modern drug therapy of epilepsy is complicated by the inability of drugs to control seizure in some patients and by their adverse effects ranging from minimal impairment of the central nervous system to death due to aplastic anemia or hepatic failure. Thus, effective and safe therapy of epilepsy remains a challenge [4].

Approximately $30 \%$ of the patients continue to have seizures with current antiepileptic drug therapy [5]. Cultural attitudes, lack of prioritization of epilepsy as a public health condition, poor wellbeing framework foundation, and lack of supply of antiepileptic drug plot to upset suitable treatment $[6,7]$. The point of treating an epileptic patient is not only to eliminate the event of seizures but also to lead a selfsustained life [5]. Hence, there is a need to look for more effective and safer alternative antiepileptic agents.

Traditional medicine continues to serve a large segment of the population regardless of the advent of modern medicine. The efficacy and safety of these remedies, however, have to be demonstrated through scientific evaluation to prove their therapeutic importance [8]. Previous studies have shown that some of the medicinal plants traditionally used for the treatment of epilepsy possessed promising anticonvulsant activities in animal models, suggesting their potential as sources of newer antiepileptic drugs [9-11].

Artemisia afra (family: Asteraceae) named "African wormwood", also locally known as "Ariti" in Ethiopia, is one of the several claimed herbal medicines used for the treatment of epilepsy [12]. Its other uses include cough, fever, colic, headache, intestinal parasitic diseases, and malaria treatment. Its roots, stems, and leaves are used for the treatments in the form of enemas, poultices, infusions, lotion, or inhalations $[13,14]$. The plant grows widely in Ethiopia, specifically in Bale, Oromia Region [12]. Consequently, this study was framed to investigate the antiepileptic effects of the hydroethanolic extract and solvent fractions of A. afra, in mouse models.

\section{Materials and Methods}

2.1. Plant Materials Preparation. The entire piece of $A$. afra (family: Asteraceae) was collected from Bale National Park, Ethiopia, $550 \mathrm{~km}$ away from Addis Ababa, and transported in a dark plastic bag to avoid decomposition by light. It was authenticated and given a voucher number (AAU-NH 02T) at the National Herbarium Museum of Ethiopia, and the plant specimen was deposited for future reference at the National Herbarium, College of Computational and Natural Sciences, Addis Ababa University. The whole fresh plant parts were dried at room temperature under the shade and then powdered using a pestle and mortar. A total of $800 \mathrm{~g}$ dried powder was macerated in $70 \% \mathrm{v} / \mathrm{v}$ of ethanol for three days, continuously stirred using an orbital shaker at $120 \mathrm{rpm}$. The extract was then filtered using gauze $(0.1 \mathrm{~mm}$
2 mesh) and Whatman filter paper (size $15 \mathrm{~cm}$ ) (Whatman ${ }^{\circledR}$ England), and the filtrate was kept in a deep freezer at $-27^{\circ} \mathrm{C}$ and then lyophilized for a week $\left(-52^{\circ} \mathrm{C}, 133 \times 10-3 \mathrm{mbar}\right)$. A total yield of $96.08 \mathrm{~g}$ crude extract was obtained and kept in a tightly closed aluminum foil in a desiccator until used.

The crude extract of $A$. afra was further fractionated using petroleum ether, dichloromethane, ethanol, and water as solvents in order to decrease polarity.

Thirty grams of a hydroethanolic extract of $A$. afra was dissolved in a separatory funnel in $100 \mathrm{ml}$ of distilled water. The dissolved extract was partitioned with $3 \times 150 \mathrm{ml}$ of petroleum ether at $40-60^{\circ} \mathrm{C}$, and the partition was concentrated using a rota-vapor to yield $2.32 \mathrm{~g}$ of petroleum ether fraction. The aqueous residue was then partitioned with $3 \times 150 \mathrm{ml}$ of dichloromethane, and the filtrate was evaporated to yield $3.78 \mathrm{~g}$ of dichloromethane fraction. The remaining aqueous residue was further partitioned with $3 \times 100 \mathrm{ml}$ ethanol, and the fractionate was concentrated to yield $4.85 \mathrm{~g}$ ethanol fraction. The leftover aqueous residue was then dried using a lyophilizer to yield $9.56 \mathrm{~g}$ aqueous residue. The fractions were then kept in a separate tightly closed container with aluminum foil in a desiccator until used.

\subsection{Drugs/Chemicals/Test Substances Preparation and} Administration. Pentylenetetrazol (Sigma Chemical Co., Sweden), diazepam (Medifarma Pharmaceuticals), and sodium chloride (BDH, England) were used in this study. All chemicals were prepared freshly just before use. The organic solvent dimethyl sulfoxide (DMSO), ethanol, dichloromethane, and petroleum ether (Germany) were used in the study. PTZ and diazepam were dissolved in saline solution $(0.9 \% \mathrm{w} / \mathrm{v})$. The crude extract and its fractions were dissolved in distilled water and DMSO (2:1 v/v) mixture. Drug solutions were prepared according to the supplier's instructions.

The maximum volume of freshly prepared herbal medicine administered at once in rodents was $1 \mathrm{ml} / 100 \mathrm{~g}$ body weight according to OECD guidelines [15]. The starting dose of $A$. afra crude extract to be administered was $250 \mathrm{mg} / \mathrm{kg}$ body weight, and $1 / 10^{\text {th }}$ of $\mathrm{LD}_{50}$ was considered as a middle dose, based on the previous study $[13,16]$.

2.3. Experimental Procedure. Male BALB/c mice weighing between 22 and $30 \mathrm{~g}$ were obtained from Ethiopian Public Health Institute, Addis Ababa, Ethiopia, and housed at room temperature under standard nutritional and environmental conditions with relative moisture of $30-70 \%$ and 12 -hour light-dark cycle. They all had access to water and food ad libitum and were denied food $12 \mathrm{~h}$ before experimentation. The animals were arbitrarily assigned to 9 treatment groups consisting of 6 mice each.

Group I received the vehicle (normal saline $(10 \mathrm{ml} / \mathrm{kg}$ ) p.o.) and served as a negative control; group II received diazepam ( $2 \mathrm{mg} / \mathrm{kg}$, p.o.), the standard drug, and served as a positive control; groups III, IV, and V received three different doses $(250,500$, and $1000 \mathrm{mg} / \mathrm{kg})$ of the crude extract; and groups VI-IX received $1000 \mathrm{mg} / \mathrm{kg}$ of the four solvent 
fractions each (petroleum ether, dichloromethane, ethanol, and aqueous), $30 \mathrm{~min}$ before subcutaneous injection of PTZ $(80 \mathrm{mg} / \mathrm{kg})$ into the loose skin fold on the back of the neck of the animals. After PTZ administration, mice were placed in a testing chamber and closely observed for the onset of convulsions and the duration of convulsion for $30 \mathrm{~min}$. Delayed onset and decreased duration of convulsions indicate the ability of the substance to protect animals from PTZ-induced convulsion, which is serving as a guide for the study of anticonvulsant activity.

2.4. Statistical Analysis. All results were expressed as mean \pm SEM. Statistical significance between the groups was analyzed by one-way analysis of variance (Sigma Plot 14 (Sigma Plot Software, Inc., La Jolla, CA, USA) software) followed by Tukey's post hoc multiple comparison test for comparison between groups. For the tests, $p<0.05$ was considered statistically significant.

2.5. Ethical Considerations. The protocol was approved by the Institutional Review Board, College of health sciences, Addis Ababa University (protocol number: 053/15/Physio). Before, during, and after the study, animals were handled according to OECD guidelines [15].

\section{Results}

3.1. Yields of Hydroethanolic Extract and Its Solvent Fraction of Artemisia afra. The yields of the crude extract and the solvent fractions of $A$. afra crude extract are shown in $\mathrm{Ta}-$ bles 1 and 2, respectively.

\subsection{Effect of the Crude Extract on the Onset of PTZ-Induced} Convulsion. The three doses $(250,500$, and $1000 \mathrm{mg} / \mathrm{kg})$ of crude extract of $A$. afra used showed a significant delay $\left(504.833 \pm 62.835^{*} \mathrm{~s} ; \quad p<0.05^{*} ; \quad 551.833 \pm 47.69^{* *} \mathrm{~s} ; \quad p<\right.$ $0.01^{* *}$; and $808.333 \pm 64.8^{* * *} \mathrm{~s} ; p<0.001^{* * *}$, respectively), in the mean onset of PTZ-induced convulsion $(p<0.05$, $p<0.01, p<0.001$, respectively), in a dose-dependent manner compared to the negative control (92.833 \pm $13.006 \mathrm{~s})$. The delay in the onset of convulsion was significantly less than that of diazepam $(1001.167 \pm 68.430 \mathrm{~s})$ as shown in Figure 1.

\subsection{Effect of the Crude Extract on the Duration of Convulsions.} The crude extract of $A$. afra significantly decreased the duration of PTZ-induced convulsions at 250, 500, and $1000 \mathrm{mg} / \mathrm{kg}$ doses $\left(17.000 \pm 1.88^{*} \mathrm{~s}, \quad p<0.05^{*} ; 13.000\right.$ $\pm 1.8^{* *} \mathrm{~s}, \quad p<0.01^{* *}$; and $7.833 \pm 1.07^{* * *} \mathrm{~s}, \quad p<0.001^{* * *}$, respectively) against $\mathrm{PTZ}$-induced convulsion compared to the negative control $(34.167 \pm 3.683 \mathrm{~s})$ in a dose-dependent manner, but the duration was significantly less long than that of diazepam $(4.500 \pm 0.619 \mathrm{~s})$ as shown in Figure 2.

\subsection{Effect of the Solvent Fraction on the Onset of PTZ-Induced} Convulsion. No significant difference was observed with all solvent fractions on the onset of PTZ-induced convulsion
TABLE 1: Yield of crude extract of hydroethanolic (70\% ethanol) extracts of $A$. afra.

\begin{tabular}{lcc}
\hline Plant material & $\begin{array}{c}\text { The total yield of } \\
\text { extract }(\mathrm{g})\end{array}$ & $\begin{array}{c}\text { Percentage of } \\
\text { yield }(\%)\end{array}$ \\
\hline $\begin{array}{l}\text { Hydroethanolic extract of } \\
\text { A. afra }\end{array}$ & 96.08 & 12.01 \\
\hline
\end{tabular}

compared to the negative control, but the difference was significant than that of diazepam $(p<0.05)$ as indicated in Figure 3 .

3.5. Effect of the Solvent Fraction on the Duration of Convulsion. The solvent fractions of $A$. afra did not show a significant difference on the duration of PTZ-induced convulsion compared to the negative control, but the difference was significant than that of diazepam $(p<0.05)$ as indicated in Figure 4.

\section{Discussion}

Pentylenetetrazol exerts its convulsant effects by inhibiting the activity of GABA at $\mathrm{GABA}_{\mathrm{A}}$ receptors, which resulted in inhibition of GABA-ergic neurotransmission in the central nervous system $[17,18]$.

GABA-ergic neurotransmission is closely associated with the induction of epilepsy in animals. The enhancement of GABA neurotransmission attenuates convulsions, while inhibition of the neurotransmission of GABA enhances convulsions [19].

GABA is an endogenous agonist of the $\mathrm{GABA}_{\mathrm{A}}$ receptor (ionotropic receptor) facilitating the opening of the channels to chloride ions in the neuronal membrane leading to hyperpolarization resulting in impeding action potential transmission and hence responsible for the antiepileptic effects of the drugs that directly bind and activate $G_{A B A}$ receptors or influence GABA release, transport, and metabolism. GABA-mediated chloride channel GABA-benzodiazepine receptor complexes are closely associated with the induction and onset of seizures [18, 19].

PTZ also increases the free radicals in the brain that leads to neuronal damage-induced epilepsy [20]. It can be considered a model for human generalized and absence seizures $[21,22]$.

Diazepam, which generally inhibits sodium currents and potentiates GABA transmission or enhances GABA-mediated inhibition in the brain, is employed as a standard antiepileptic drug in experiments that target the search for new antiepileptic agents as it blocks PTZ-induced convulsions [23].

The present study showed that the hydroethanolic extract of Artemisia afra, delayed the onset and decreased the duration of PTZ-induced convulsions in a dose-dependent manner.

This finding is in agreement with other studies which also showed the anticonvulsant effects of pycnogenol extract [24], the aqueous extract of Antiaris toxicaria stem bark [25], hydroethanolic Phoenix dactylifera fruit extract, and Pimpinella anisum oil [26]. 
TABLE 2: Yields of the solvent fraction of $30 \mathrm{gm}$ of $70 \%$ ethanol crude extract of A. afra.

\begin{tabular}{lccc}
\hline Plant material & Type of fraction & Weight of fraction obtained $(\mathrm{g})$ & Percentage of yield (\%) \\
\hline & Petroleum ether fraction & 2.32 & 11.6 \\
A. afra & Dichloromethane fraction & 3.78 & 18.9 \\
& Ethanol fraction & 4.85 & 24.25 \\
& Aqueous residue & 9.56 & 47.8 \\
\hline
\end{tabular}

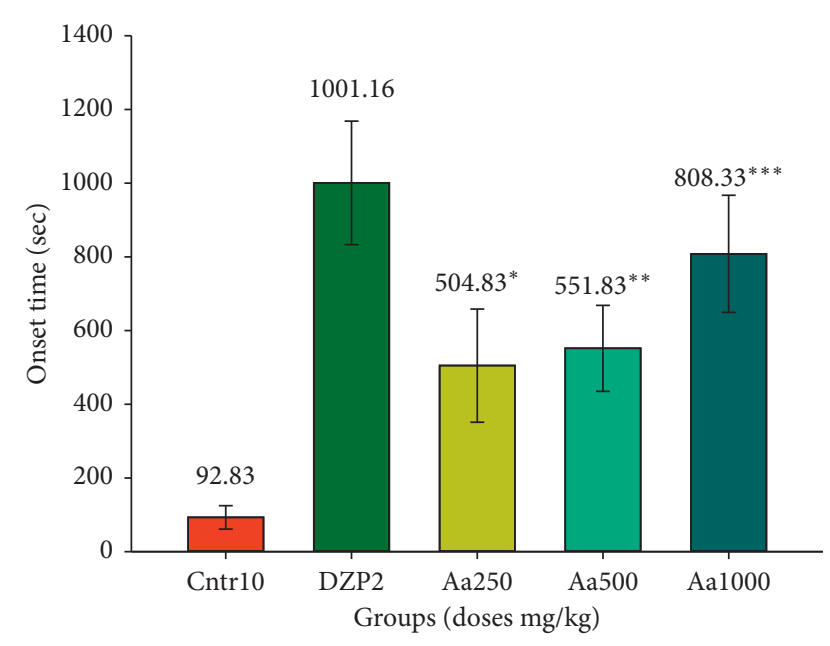

Figure 1: Mean onset of convulsions with hydroethanolic $A$. afra crude extract $(250 \mathrm{mg} / \mathrm{kg}, 500 \mathrm{mg} / \mathrm{kg}$, and $1000 \mathrm{mg} / \mathrm{kg}) 30 \mathrm{~min}$ before subcutaneous PTZ administration compared with those of the positive (diazepam $2 \mathrm{mg} / \mathrm{kg}$ ) and negative (physiological saline $10 \mathrm{mg} / \mathrm{kg}$ ) controls. Data represent mean \pm SEM of three independent experiments ( $n=6$ for each group). SEM $=$ standard error of the mean, $\mathrm{Aa}=$ A. afra, $\mathrm{DZP}=$ diazepam, and $\mathrm{Ctrl}=$ control.

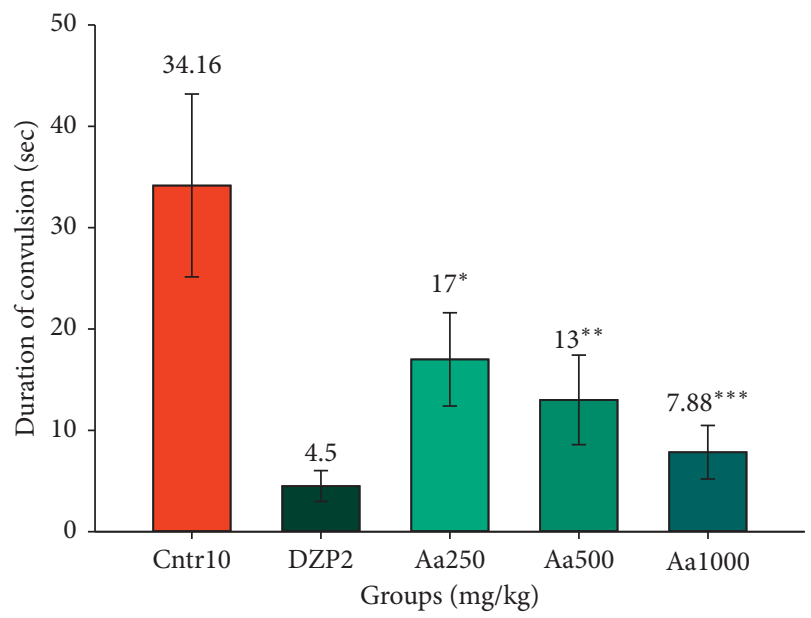

Figure 2: Mean duration of convulsions with hydroethanolic A. afra crude extract $(250 \mathrm{mg} / \mathrm{kg}, 500 \mathrm{mg} / \mathrm{kg}$, and $1000 \mathrm{mg} / \mathrm{kg})$ 30 min before subcutaneous PTZ administration compared with those of the positive (diazepam $2 \mathrm{mg} / \mathrm{kg}$ ) and negative (physiological saline $10 \mathrm{mg} / \mathrm{kg}$ ) controls. Values are mean \pm SEM of three independent experiments ( $n=6$ for each group). SEM $=$ standard error of the mean, Aa=Artemisia afra, DZP=diazepam, and Ctrl $=$ control.

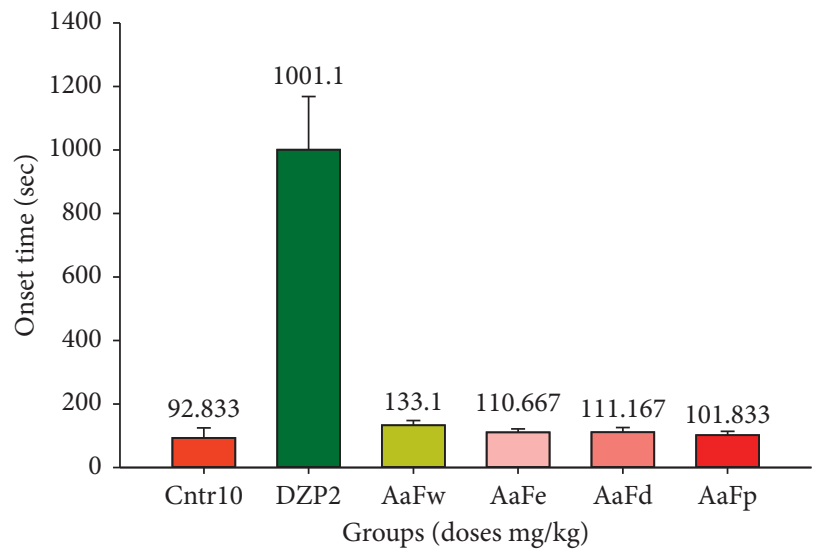

Figure 3: Mean onset of convulsion with $1000 \mathrm{mg} / \mathrm{kg}$ solvent fraction of hydroethanolic $A$. afra crude extract $30 \mathrm{~min}$ before subcutaneous PTZ administration for positive (diazepam $2 \mathrm{mg} / \mathrm{kg}$ ) and negative (physiological saline $10 \mathrm{mg} / \mathrm{kg}$ ) controls. Values are mean \pm SEM of three independent experiments $(n=6$ for each group). $\mathrm{SEM}=$ standard error of the mean, $\mathrm{AaFw}=A$. afra water fraction, $\mathrm{AaFe}=A$. afra ethanol fraction, $\mathrm{AaFd}=A$. afra dichloromethane fraction, $\mathrm{AaFp}=$ A.afra petroleum ether fraction, $\mathrm{DZP}=$ diazepam, and $\mathrm{Ctrl}=$ control.

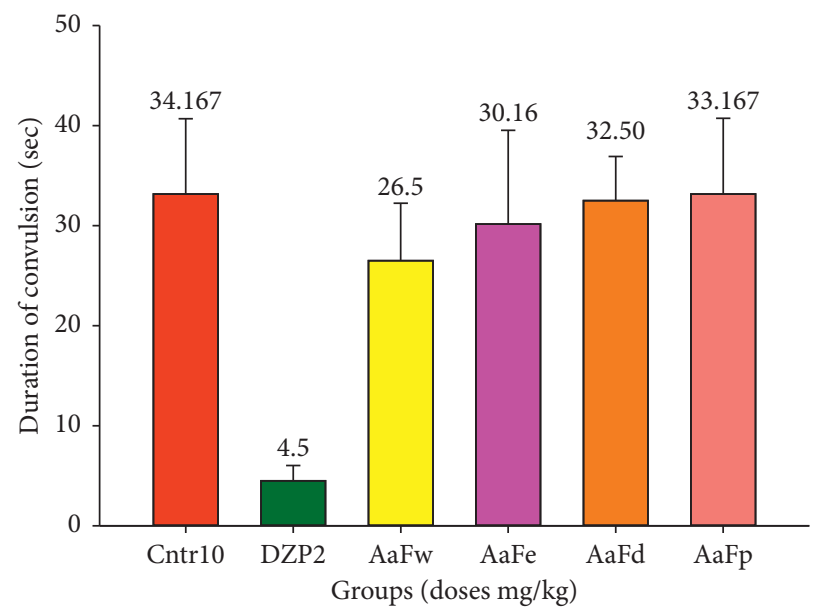

FIGURE 4: Mean duration of convulsion with $1000 \mathrm{mg} / \mathrm{kg}$ solvent fraction of hydroethanolic $A$. afra crude extract $30 \mathrm{~min}$ before subcutaneous PTZ administration for the positive (diazepam $2 \mathrm{mg}$ / $\mathrm{kg}$ ) and negative (physiological saline $10 \mathrm{mg} / \mathrm{kg}$ ) control groups ( $n=6$ for each group). Values represent mean \pm SEM of three independent experiments ( $n=6$ for each group). SEM $=$ standard error of the mean, $\mathrm{AaFw}=A$. afra water fraction, $A a F e=A$. afra ethanol fraction, $\mathrm{AaFd}=A$. afra dichloromethane fraction, $\mathrm{AaFp}=A$. afra petroleum ether fraction, $\mathrm{DZP}=$ diazepam, and Ctrl $=$ control. 
The ability of the extracts to delay the onset and/or shorten the duration of convulsions was considered an indication of anticonvulsant activity $[25,27]$.

As the crude extract prevented PTZ-induced convulsion, the mechanism for the anticonvulsant effect of the crude extract might be associated with the activity on GABA synapses which diazepam acts on as well [17, 28].

The medicinal value of the plants lies in some chemical constituents (phytochemicals) that produce a definite physiological function as an anticonvulsant agent.

The most important of the bioactive constituents of the extracts are alkaloids, tannins, flavonoids, and phenolic compounds [29, 30].

This is in agreement with studies in which alkaloids, flavonoids, terpenoids, saponins, and coumarins were found to enhance GABA transmission to exert their anticonvulsant effect. Therefore, these phytochemicals may be responsible for the anticonvulsant activity observed in this study [31-34].

In contrast to the anticonvulsant activity observed in the crude extract, none of the solvent fractions demonstrated a significant anticonvulsant effect. This might be due to the too low concentrations of phytochemicals that are present in each solvent fraction to produce the expected effect. This is so because partitioning of the phytochemicals of the crude extract in different solvents may reduce the concentration to be present in each fraction. It might also be due to the loss of some phytochemicals undergoing decomposition during the partitioning process in contrast to what has been observed in another study where the solvent fractionation of Ebenus stellata crude extract did not reduce convulsion [35].

Our finding on solvent fractions is, however, in agreement with that of a previous study [36]. The anticonvulsant effect observed only in the crude extract might be attributed to the synergistic and/or additive effects as well as the higher concentration of the active ingredients present [37].

\section{Conclusion}

In summary, the results presented here indicate that the hydroethanolic crude extract obtained from Artemisia afra significantly delayed the onset and prevented the severity of PTZ-induced convulsions, indicating its anticonvulsant activity. While, the solvent fractionation of the hydroethanolic extract of the plant did not induce such effects, demonstrating a combination of different biologically active components in the hydroethanolic extract of the plant.

However, further studies are needed using different animal models for understanding underlying mechanism(s), and the active principles involved in these effects need to be explored.

The observed anticonvulsant effects confirm and justify the ethnomedicinal use of the plant in the management of epilepsy, as well as preserving the environment and its biodiversity.

\section{Data Availability}

The datasets utilized or potentially examined during the analysis are accessible from the corresponding author and coauthors on demand, besides included in the supplementary materials file.

\section{Conflicts of Interest}

The authors declare that they have no conflicts of interest.

\section{Acknowledgments}

The authors would like to thank the School of Graduate Studies, Addis Ababa University, for financing this study through a thematic research grant (RD/LT/181/2013; August 1, 2013). The authors also acknowledge the Departments of Physiology, Pharmacology, and Pharmacognosy, Addis Ababa University and the College of Natural and Computational Sciences of Arbaminch University for providing laboratory working space together with relevant equipment to perform this study.

\section{Supplementary Materials}

The datasets utilized or potentially examined during the analysis are included in the supplementary materials file. (Supplementary Materials)

\section{References}

[1] Y. Zhu, S. Zhang, M. Shen et al., "Anticonvulsant effects of dingxian pill in pentylenetetrazol-kindled rats," EvidenceBased Complementary and Alternative Medicine, vol. 2019, Article ID 4534167, 10 pages, 2019.

[2] S. K. Rout and D. M. Kar, "Sedative anxiolytic and anticonvulsant effects of different extracts from the leaves of Ipomoea carnea in experimental animals," International Journal of Drug Development and Research, vol. 5, no. 2, pp. 232-243, 2013.

[3] M. J. Brodie, S. M. Zuberi, I. E. Scheffer, and R. S. Fisher, “The 2017 ILAE classification of seizure types and the epilepsies: what do people with epilepsy and their caregivers need to know?” Epileptic Disorders, vol. 20, no. 2, pp. 77-87, 2018.

[4] S. S. Twinomujuni, J. Oloro, and P. E. Alele, "Anticonvulsant and anxiolytic activity of the leaf aqueous and ethanolic extracts of Melanthera scandens in a rat model," African Journal of Pharmacy and Pharmacology, vol. 10, no. 12, pp. 216-222, 2016.

[5] R. S. Fisher, J. H. Cross, J. A. French et al., "Operational classification of seizure types by the international league against epilepsy: position paper of the ILAE commission for classification and terminology," Epilepsia, vol. 58, no. 4, pp. 522-530, 2017.

[6] Y. Wang and Z. Chen, "An update for epilepsy research and anti-epileptic drug development: toward precise circuit therapy," Pharmacology and Therapeutics, vol. 201, pp. 77-93, 2019.

[7] P. Amoateng, E. Woode, and S. B. Kombian, “Anticonvulsant and related neuropharmacological effects of the whole plant extract of Synedrella nodiflora (L.) Gaertn (Asteraceae)," Journal of Pharmacy \& Bioallied Sciences, vol. 4, no. 2, p. 140, 2012.

[8] A. G. Singh, A. Kumar, D. D. Tewari, and K. A. Bharati, "New ethnomedicinal claims from magar community of Palpa 
district Nepal," Indian Journal of Traditional Knowledge, vol. 17, 2018.

[9] P. Wlaź, K. Socała, D Nieoczym et al., “Acute anticonvulsant effects of capric acid in seizure tests in mice," Progress in Neuro-Psychopharmacology \& Biological Psychiatry, vol. 57, pp. 110-116, 2015.

[10] H. K. Nagar, A. K. Srivastava, R. Srivastava, M. L. Kurmi, H. S. Chandel, and M. S. Ranawat, "Pharmacological investigation of the wound healing activity of Cestrum nocturnum (L.) ointment in Wistar albino rats," Journal of Pharmaceutics, vol. 2016, Article ID 9249040, 8 pages, 2016.

[11] D. M. Benjumea, I. C. Gómez-Betancur, J. Vásquez, F. Alzate, A. García-Silva, and J. A. Fontenla, "Neuropharmacological effects of the ethanolic extract of Sida acuta," Revista Brasileira de Farmacognosia, vol. 26, no. 2, pp. 209-215, 2016.

[12] H. Yineger, E. Kelbessa, T. Bekele, and E. Lulekal, "Plants used in traditional management of human ailments at bale mountains national park southeastern Ethiopia," Journal of Medicinal Plants Research, vol. 2, no. 6, pp. 132-153, 2008.

[13] I. A. Issa and M. Hussen Bule, "Hypoglycemic effect of aqueous and methanolic extract of Artemisia afra on alloxan induced diabetic Swiss albino mice," Evidence-based Complementary and Alternative Medicine, vol. 2015, Article ID 752486, 5 pages, 2015.

[14] S. Malami, H. Kyari, N. M. Danjuma, J. Ya'u, and I. M. Hussaini, "Anticonvulsant properties of methanol leaf extract of Laggera Aurita Linn. F. (Asteraceae) in laboratory animals," Journal of Ethnopharmacology, vol. 191, pp. 301306, 2016.

[15] J. Buschmann, The OECD Guidelines for the Testing of Chemicals and Pesticides, Humana Press, Totowa, NJ, USA, 2013.

[16] N. Eshetu, M. Afework, E. Makonnen, A. Debella, W. Ergete, and T. Tolesssa, "Evaluation of the acute and sub-chronic toxic effects of aqueous leaf extracts of Artemisia afra on liver, kidney and some blood parameters in wistar rats," Advances in Bioscience and Bioengineering, vol. 4, no. 1, pp. 1-9, 2016.

[17] I. A. Bukhari, N. Pivac, M. S. Alhumayyd, A. L. Mahesar, and A. H Gilani, "The analgesic and anticonvulsant effects of piperine in mice," Journal of Physiology and Pharmacology, vol. 64, no. 6, pp. 789-94, 2013.

[18] I. Khan, N. Karim, W. Ahmad, A. Abdelhalim, and M. Chebib, "GABA-A receptor modulation and anticonvulsant anxiolytic and antidepressant activities of constituents from Artemisia indica Linn," Evidence-Based Complementary and Alternative Medicine, vol. 2016, Article ID 1215393, 12 pages, 2016.

[19] A. M. Tamboli, R. A. Rub, P. Ghosh, and S. Bodhankar, "Antiepileptic activity of lobeline isolated from the leaf of Lobelia nicotianaefolia and its effect on brain GABA level in mice," Asian Pacific Journal of Tropical Biomedicine, vol. 2, no. 7, pp. 537-542, 2012.

[20] G. S. Taiwe, T. B. Tchoya, J. R. Menanga, B. Dabole, and M. De Waard, "Anticonvulsant activity of an active fraction extracted from Crinum jagus L. (Amaryllidaceae), and its possible effects on fully kindled seizures, depression-like behaviour and oxidative stress in experimental rodent models," Journal of Ethnopharmacology, vol. 194, pp. 421-433, 2016.

[21] B. P. Grone and S. C. Baraban, "Animal models in epilepsy research: legacies and new directions," Nature Neuroscience, vol. 18, no. 3, pp. 339-343, 2015.

[22] E. Randrianarivo, F. Maggi, M. Nicoletti, and P. Rasoanaivo, "Evaluation of the anticonvulsant activity of the essential oil of Myrothamnus moschatus in convulsion induced by pentylenetetrazole and picrotoxin," Asian Pacific Journal of Tropical Biomedicine, vol. 6, no. 6, pp. 501-505, 2016.
[23] M. Shinde, R. Gilhotra, and S. Chaudhari, "Anticonvulsant and sedative activities of extracts of carissa carandas leaves," Journal of Drug Delivery and Therapeutics, vol. 8, no. 5, pp. 369-373, 2018.

[24] R. Goel and P. Saxena, "Pycnogenol protects against pentylenetetrazole-induced oxidative stress and seizures in mice," Current Clinical Pharmacology, vol. 14, no. 1, pp. 68-75, 2019.

[25] P. K. Mante, D. W. Adongo, E. Woode, K. K. E. Kukuia, and E. O. Ameyaw, "Anticonvulsant effect of Antiaris toxicaria (Pers.) Lesch. (Moraceae) Aqueous Extract in Rodents," ISRN Pharmacology, vol. 2013, Article ID 519208, 9 pages, 2013.

[26] S. Mohamed Mostafa, S. A. Ahmed, M. Salah Moselhi, and M. Giorgi, "Anticonvulsant activity of hydro-alcoholic Phoenix dactylifera Fruit extract and Pimpinella anisum oil in mice," American Journal of Animal and Veterinary Sciences, vol. 14, no. 2, pp. 127-138, 2019.

[27] T. E. Kediso, T. Tolessa, F. Getachew, E. Makonnen, and D. Seifu, "Evaluation of hydro-alcoholic extract of Clerodendrum myricoides (hochst. Vatke) leaves and its solvent fractionsin pentylenetetrazole-induced convulsion in mice," Journal of Complementary and Alternative Medical Research, vol. 10, 2020.

[28] S. C. Sarangi, S. S. Pattnaik, J. Katyal, T. Kaleekal, and A. K. Dinda, "An interaction study of Ocimum sanctum L. and levetiracetam in pentylenetetrazole kindling model of epilepsy," Journal of Ethnopharmacology, vol. 249, Article ID 112389, 2020.

[29] M. M. Amin, S. S. Sawhney, and M. M. S. Jassal, "Qualitative and quantitative analysis of phytochemicals of Taraxacum officinale," African Journal of Pharmacy and Pharmacology, vol. 2, no. 1, pp. 001-005, 2013.

[30] N. F. Kane, M. C. Kyama, J. K. Nganga, A. Hassanali, M. Diallo, and F. T. Kimani, "Comparison of phytochemical profiles and antimalarial activities of Artemisia afra plant collected from five countries in Africa," South African Journal of Botany, vol. 125, pp. 126-133, 2019.

[31] P. Singh, D. Singh, and R. K. Goel, "Phytoflavonoids: antiepileptics for the future," Channels (Retigabine), vol. 3, p. 5, 2014.

[32] S. Zeb, A. Ali, W. Zaman et al., "Pharmacology taxonomy and phytochemistry of the genus Artemisia specifically from Pakistan: a comprehensive review," Pharmaceutical and Biomedical Research, vol. 4, 2019.

[33] T. Abera, R. Ashebir, H. Basha et al., "Phytochemical-constituents, safety and efficacy of commonly used medicinal plants for the treatment of malaria in Ethiopia-a review," Pharmacy \& Pharmacology International Journal, vol. 7, no. 6, pp. 284-295, 2019.

[34] H. Son and P. Yen, "Preliminary phytochemical screening, acute oral toxicity and anticonvulsant activity of the berries of Solanum nigrum linn," Tropical Journal of Pharmaceutical Research, vol. 13, no. 6, pp. 907-912, 2014.

[35] A. Khodaparast, M. Sayyah, and S. Sardari, "Anticonvulsant activity of hydroalcoholic extract and aqueous fraction of Ebenus stellata in mice," Iranian Journal of Basic Medical Sciences, vol. 15, pp. 811-819, 2012.

[36] F. Zolfagharian, B. M. Razavi, and H. Hosseinzadeh, "Anticonvulsant effect of Satureja hortensis aerial parts extracts in mice," Avicenna Journal of Phytomedicine, vol. 6, no. 3, pp. 305-12, 2016.

[37] J. M. McPartland and E. B. Russo, "Future of cannabis and cannabinoids in therapeutics, Cannabis," Cannabis and Cannabis Extract: Greater than the Sum of their Parts? The Handbook of Cannabis Therapeutics: from Bench to bedside, 2014. 